\title{
A Presença de Castello (1921-2011) ${ }^{1}$
}

Telê Ancona Lopez ${ }^{2}$ e Antonio Dimas ${ }^{3}$

Em 2001, quando José Aderaldo Castello se tornou professor emérito da Faculdade de Filosofia, Letras e Ciências Humanas da Universidade de São Paulo, os amigos homenagearam-no com um livro, no qual uma cronologia mostra os ricos caminhos de um intelectual brasileiro e deste professor da literatura de nosso país. Esses caminhos, matéria de memória daqueles que com ele conviveram, demonstram a contribuição substantiva de seus livros e artigos; dos trabalhos universitários que orientou; de suas aulas bem preparadas, escandidas a sotto voce, tudo lição viva do mestre da Faculdade e do Instituto de Estudos Brasileiros. Perdemos, todavia, o ganho intelectual e afetivo, o gosto maior da conversa informal em torno de autores, livros e revistas, consultas disfarçadas que nos enleavam por horas e horas.

Os alunos, amigos e colegas desta Universidade - e fora dela, no Brasil e no exterior - bem sabem que as sementes e a lavra do Prof. Castello perduram, como propostas de trabalho ou linhas de pesquisa, na formação dos estudiosos da literatura brasileira. Consolidam-lhe o compromisso acadêmico de transmitir o conhecimento, almejando suscitar novos saberes.

Três vertentes, entre outras de importância igual, marcam especialmente a contribuição de Castello.

A primeira delas é a recuperação exigente e minuciosa das fontes primárias, essenciais para a compreensão do nosso passado literário, situando-o no contexto histórico, cultural e artístico. Fundamental foi sua investigação dessas fontes, sobretudo no período que antecede a Independência. Assim fez Castello e mostrou aos seus alunos como se pode e se deve fazer. Entre 1957 e 1980, o Professor empreendeu investigação ambiciosa sobre o movimento academicista e os atos acadêmicos, até hoje pouco avaliado. Descobriu e fotografou material inédito com que se ocupou em suas aulas, divulgando-o e explorando-o, dele nos deixando os dezessete volumes de documentos de seu $O$ movimento academicista

1 Publicado originalmente no Informe-Informativo da Faculdade de Filosofia, Letras e Ciências Humanas, seção Em memória. n. 67, mar./abr. 2012, p. 6-7.

2 Colaboradora sênior de Literatura Brasileira do Instituto de Estudos Brasileiros da Universidade de São Paulo.

3 Professor titular do Departamento de Letras Clássicas e Vernáculas da Faculdade de Filosofia, Letras e Ciências Humanas da Universidade de São Paulo. 
no Brasil e a sua cuidadosa análise das Manifestações literárias da era colonial. Essa pesquisa, em 1962, alinhou-o entre os primeiros a receber recursos da Fapesp na área de Letras, junto de Antonio Candido, responsável pela investigação em torno de Mário de Andrade. Cada um, a seu modo, deu início à profissionalização da pesquisa em Letras neste país, graças à retaguarda institucional e financeira da Fapesp, recémnascida no Governo Carvalho Pinto, em 1961.

A pesquisa, que garantiu a originalidade de Castello em sua produção de historiador e crítico, tomou por objeto escritores, movimentos e obras, percorrendo o Brasil colônia, o romantismo e o realismo, o regionalismo nordestino, Machado de Assis e o modernismo. Graças a ela, Castello alicerçou o processo comparativo que lhe trouxe a aproximação unificadora, o sentido de "auto-identificação" da literatura brasileira, considerando os "legados europeus e americanos", conforme se expressa em sua obra magna, A literatura brasileira: Origens e unidade (15001960). Associada ao propósito didático de difundir mais amplamente nossas estéticas literárias, a pesquisa moveu Aderaldo Castello e Antonio Candido a publicar, em 1964, A presença da literatura brasileira, antologia de título tão sugestivo, repartida em três volumes: Das origens ao romantismo, Do romantismo ao simbolismo e Modernismo. Este focalizando, pela primeira vez, o movimento renovador em termos de panorama de autores e textos.

$\mathrm{Na}$ orientação de pesquisas acadêmicas, decalcada nas fontes primárias, Castello inaugurou nos anos de 1970, o estudo de revistas literárias. Essa iniciativa, de importância hoje reconhecida, dilatou os limites do conhecimento da nossa historiografia literária, porque permitiua recuperação de informações essenciais para sua modelagem contemporânea, bem como nos trouxe de volta periódicos como Minerva Brasiliense, Guanabara, Rosa-Cruz, Kosmos, Movimento Brasileiro, Festa, Klaxon, Estética, Arco \& Flexa e outras. Sem contar que - aqui ou ali, logo ou depois - ainda impulsionou, como decorrência, a republicação fac-similar de outras revistas tais como Klaxon, Verde, Terra Roxa, O pão da padaria espiritual, Estética, Joaquim, Arco \& Flexa etc. Os doutoramentos e mestrados que brotaram dessa nova metodologia, na Universidade de São Paulo ou fora dela, moldam um conjunto valioso em que os documentos afiançam traços e ressaltam nuances de um período.

A segunda vertente diz respeito à salvaguarda do patrimônio histórico e artístico do Brasil, em ligação estreita com a pesquisa. Em 1968, ao suceder o grande historiador de nossa cultura, Sérgio Buarque de Holanda, na direção do Instituto de Estudos Brasileiros, entidade 
interdisciplinar por ele criada na USP, o Prof. José Aderaldo Castello mostrou-se gestor atento à organização moderna de fundos documentais, bibliotecas e coleções de arte; à difusão da riqueza ali existente e da pesquisa ali realizada. Exposições, catálogos, conferências e cursos, bem como encontros de pesquisadores, deram ao IEB repercussão nacional e internacional. Nos anos 1960 e 1970, os cursos de férias sobre o Cangaço, sobre a Década de 1920, a de 1930 e a de 1940 brilharam como conjuntos bem articulados de palestras interdisciplinares. Ministradas por Antonio Candido, Paulo Emílio Salles Gomes, Décio de Almeida Prado, Sábato Magaldi, Cavalcanti Proença, Maria Isaura Pereira de Queiroz, Anatol Rosenfeld, Afonso Arinos, José Ramos Tinhorão e outros nomes de quilate semelhante, esses cursos abriram também espaço para os jovens pesquisadores concursados, do quadro da instituição. Levando adiante a ideia do Prof. Antonio Candido, que propunha um centro de excelência nos estudos do modernismo, a incorporação do Acervo Mário de Andrade ao IEB multiplicou pesquisas que entrelaçam literatura, artes plásticas e música.

A terceira das vertentes é Castello editor, nos anos de 1970. Não apenas quem pôs a Revista do IEB em pé, como aquele que criou a BULB, Biblioteca Universitária de Literatura Brasileira, dedicada a edições críticas de obras e a coletâneas de textos essenciais da história e da crítica, dentro da qual foram publicadas Senhora, Macunaíma, Memórias de um sargento de milícias, Decadismo e simbolismo no Brasil, Historiadores e críticos do romantismo. Nesta vertente editorial, ele integrou também o antigo Conselho Estadual de Literatura do governo paulista, cuja lista de resultados este espaço não comporta.

Incorporado ao patrimônio do IEB, o acervo do Professor José Aderaldo Castello, nas fichas, nos manuscritos de ensaios, nos livros cheios de anotações do leitor, nas edições raras, franqueia o cotidiano de uma pródiga carreira acadêmica.

Legado e lição. 



\section{Missão}

A Revista do Instituto de Estudos Brasileiros (Revista IEB) tem por missão refletir sobre a sociedade brasileira articulando múltiplas áreas do saber. Nesse sentido, empenha-se na publicação de artigos originais e inéditos, resenhas e documentos relacionados aos estudos brasileiros.

\section{Critérios para a apresentação e publicação de artigos}

\section{Condições gerais}

- A Revista do Instituto de Estudos Brasileiros publica artigos em português e espanhol.

- Os artigos a serem apresentados para apreciação e eventual publicação pela Revista do Instituto de Estudos Brasileiros deverão ser encaminhados em formato digital e impresso, em 1 via.

- Os artigos serão submetidos à avaliação de dois (2) pareceristas, sendo considerada a autenticidade e originalidade do trabalho.

a. Em caso de divergência será ouvido um terceiro parecerista.

b. Os pareceristas têm 30 dias para emitirem seus pareceres.

c. O prazo médio de resposta para os autores é de quatro (4) meses.

- A revista reserva-se o direito de adequar o material enviado ao seu projeto editorial.

- Todo artigo deverá vir acompanhado de declaração do seu autor nos seguintes termos:

Autorizo a Revista do Instituto de Estudos Brasileiros a publicar o artigo [colocar o título], de minha autoria, assim como me responsabilizo pelo ineditismo do mesmo e, também, pela cessão dos autores quanto ao uso das imagens, caso seja aceito para a publicação. Eu, [colocar nome completo], CPF [colocar número], RG [colocar número], residente no endereço [colocar endereço completo], assino a presente declaração como expressão absoluta da verdade e me responsabilizo integralmente, em meu nome e de eventuais coautores, pelo material apresentado. [Local e data]

A declaração deverá ser assinada e enviada ou para o seguinte endereço:

Instituto de Estudos Brasileiros

Revista do IEB

Av. Prof. Mello Moraes, travessa 8, 140

Cidade Universitária

05408-030 - São Paulo - SP

Brasil 


\section{Padronização do trabalho enviado}

2.1. Formatação

Programa: Word; dimensão da página: A4; margens: $2,5 \mathrm{~cm}$; fonte: Times Roman; corpo: 12; entrelinha: 1,5.

\subsection{Quantidade de caracteres}

- Artigos: entre 30 mil e 52 mil caracteres (incluindo espaços)

- Resenhas: entre 5 mil e 20 mil caracteres (incluindo espaços)

- Notícias e documentação: até 20 mil caracteres (incluindo espaços)

\subsection{Complementos}

- O artigo deve obedecer as normas ABNT NBR 6022/ 2003.

- Em página inicial e separada do corpo do texto devem constar: título do artigo, em português e em inglês ou outra língua estrangeira; nome(s) do(s) autor(es); filiação institucional completa (departamento, unidade, etc).

- Caso o trabalho tenha apoio financeiro de alguma instituição, esta deverá ser mencionada no início do texto, abaixo do nome do autor.

- Resumo de no máximo 10 linhas em português e em inglês.

- Palavras-chave, entre três e cinco, em português e em inglês.

- Ilustrações, gráficos e tabelas devem trazer suas respectivas legendas.

\subsection{Notas e bibliografia}

- As notas explicativas e bibliográficas devem constar no rodapé devidamente numeradas e obedecidas as disposições da ABNT. Exemplos:

1 REIS FILHO, Nestor Goulart. A urbanização $e$ o urbanismo na região das Minas. São Paulo: FAU/USP, 1999. (Cadernos do LAP, 30).

2 HOLANDA, Sérgio Buarque de. O semeador e o ladrilhador. In: Raizes do Brasil. São Paulo: Companhia das Letras, 1997. cap. 4, p. 93-138.

3 TORRÃO FILHO, Amílcar. Paradigma do caos ou cidade da conversão?: a cidade colonial na América portuguesa e o caso da São Paulo na administração do Morgado de Mateus (1765-1775). 2004. 338 f. Dissertação (Mestrado em História) - Instituto de Filosofia e Ciências Humanas, Universidade Estadual de Campinas, 2004.

4 BASTOS, Rodrigo Almeida. A arte do urbanismo conveniente: o deco- 
ro na implantação de novas povoações em Minas Gerais na primeira metade do século XVIII. In: PEREIRA, Sônia Gomes (Org.). Anais do VI Colóquio luso-brasileiro de história da arte. Rio de Janeiro: CBHA/ UFRJ/UERJ/PUC-Rio, 2004. v. 2, p. 667-677.

5 CANDIDO, Antonio. Dialética da malandragem. Revista do Instituto de Estudos Brasileiros, São Paulo, n. 8, p. 67-89, 1970.

6 MAUAD, Ana Maria. Entre retratos e paisagens: modos de ver e representar no Brasil oitocentista. Studium, Campinas, v. 15, 2004. Disponível em: http://www.studium.iar.unicamp.br/15/01.html. Acesso em: 27 fev. 2007.

\section{Responsabilidades}

- As traduções deverão ser acompanhadas de autorização do autor do texto original.

- Fica estritamente restrita ao autor do artigo a responsabilidade pela reprodução das imagens.

- A Revista não se responsabiliza pela redação nem pelos conceitos emitidos pelos colaboradores/autores dos artigos. 
